\title{
Selective Expression of Phosphoribosylpyrophosphate Synthetase Superactivity in Human Lymphoblast Lines
}

\author{
Michele J. Losman, David Rimon, Mitchel Kim, and Michael A. Becker \\ Rheumatology Section, Department of Medicine, The University of Chicago Pritzker School of Medicine, Chicago, Illinois 60637
}

\begin{abstract}
Phenotypic expression of 5-phosphoribosyl 1-pyrophosphate (PRPP) synthetase superactivity was examined in lymphoblast lines derived from six unrelated male patients. Fibroblasts from these individuals have increased rates of PRPP and purine nucleotide synthesis and express four classes of kinetic derangement underlying enzyme superactivity: increased maximal reaction velocity (catalytic defect); inhibitor resistance (regulatory defect); increased substrate affinity (substrate binding defect); and combined catalytic and regulatory defects.

Lymphoblast lines from three patients with catalytic defects and from three normal individuals were indistinguishable with respect to enzyme activities, PRPP concentrations and generation, and rates of purine synthesis. Enzyme in lymphoblasts from a patient with combined defects also showed normal maximal reaction velocity but expressed purine nucleotide inhibitor resistance. A second regulatory defect and a substrate binding defect were also demonstrable in lymphoblasts and were identical to the enzyme defects in fibroblasts from the respective patients. Regulatory and substrate binding defects in lymphoblasts were accompanied by increased rates of PRPP and purine nucleotide synthesis.
\end{abstract}

Among explanations for selective expression of enzyme superactivity, reduced concentrations of catalytically superactive enzymes seemed unlikely: immunoreactive PRPP synthetase was comparable in normal-derived and patient-derived cells. Activation of normal enzyme in transformed lymphocytes was also unlikely because absolute specific activities of lymphoblast PRPP synthetases corresponded to those of normal fibroblast and erythrocyte enzymes. Abnormal electrophoretic mobilities and thermal stabilities, identified in certain catalytically superactive fibroblast PRPP synthetases, were not found in the corresponding lymphoblast enzymes. Thus, lymphoblast PRPP synthetases from patients with catalytic superactivity appeared to differ structurally and functionally from their fibroblast counterparts.

\section{Introduction}

Superactivity of 5-phosphoribosyl 1-pyrophosphate (PRPP) ${ }^{1}$ synthetase (EC 2.7.6.1), the enzyme catalyzing synthesis of the

Address reprint requests to Dr. Becker, Rheumatology Section, University of Chicago Medical Center, 5841 South Maryland Ave., Hospital Box 404, Chicago, IL 60637.

Received for publication 29 October 1984 and in revised form 28 April 1985.

1. Abbreviations used in this paper: CRM, immunoreactive PRPP synthetase; DPBS, Dulbecco's phosphate-buffered saline; EB virus, Epstein-

J. Clin. Invest.

(C) The American Society for Clinical Investigation, Inc.

0021-9738/85/10/1657/08 $\$ 1.00$

Volume 76, October 1985, 1657-1664 purine regulatory intermediate PRPP from ATP and ribose-5phosphate (ribose-5-P) (1), is an inherited disorder in which excessive enzyme activity is associated with uric acid overproduction and gout (2-12). Erythrocytes and cultured fibroblasts from affected individuals show increases in PRPP concentration and generation as well as excessive rates of PRPP-dependent purine synthetic reactions (4-8, 13-15). Increased rates of purine synthesis de novo have been shown both in affected males in vivo $(2-4,6-8,10,11,16)$ and in their fibroblasts in vitro $(3-5,7$, $11,14,15)$. Uric acid overproduction in individuals with PRPP synthetase superactivity seems to result from increased PRPP availability with consequent acceleration of purine nucleotide synthesis. $(14,17)$.

Among the heterogeneous kinetic defects underlying PRPP synthetase superactivity are: $(a)$ catalytic defects due to increased maximal reaction velocity $(6-8,11,18) ;(b)$ regulatory defects due to diminished responsiveness to purine nucleotide inhibitors of enzyme activity $(14,19) ;(c)$ substrate binding defects resulting in increased affinity for ribose-5-P (4); and $(d)$ combined catalytic and regulatory defects (5). Studies of superactive enzymes in each of these classes $(4-8,14,18,19)$ have provided evidence for structural alteration underlying superactivity. Furthermore, enzyme superactivity is transmitted as an X chromosome-linked trait $(20,21)$, and the structural gene for the single PRPP synthetase subunit (22) has been localized to the long arm of the $\mathrm{X}$ chromosome (23). Thus, even though demonstration of an altered primary structure of the enzyme protein has not, to date, been achieved for any superactive variant, structural gene mutation as the basis of enzyme superactivity is strongly suggested.

We have studied expression of PRPP synthetase superactivity in lymphoblast lines derived from peripheral blood B lymphocytes of affected male patients and have found that regulatory and substrate binding defects in PRPP synthetase are expressed in lymphoblast lines but catalytic defects are not. Absence of expression of this class of defects in lymphoblasts seems to be selective and is accompanied by absence in the cells of metabolic properties and in the enzyme of physical and immunochemical properties which in fibroblasts and erythrocytes distinguish superactive variant and normal phenotypes.

\section{Methods}

Materials. $\left[8-{ }^{14} \mathrm{C}\right] \mathrm{adenine}(55 \mathrm{mCi} / \mathrm{mmol})$ and Omnifluor scintillator were purchased from New England Nuclear (Boston, MA); $\left[{ }^{14} \mathrm{C}\right]$ formic acid, sodium salt $(55 \mathrm{mCi} / \mathrm{mmol})$, and ${ }^{125} \mathrm{I}-\mathrm{Na}$, carrier-free $(1.9 \mathrm{Ci} / \mathrm{mmol})$ were purchased from Amersham Corp. (Arlington Heights, IL). RPMI 1640 medium, Eagle's minimal essential medium, trypsin-EDTA, L-glutamine, nonessential amino acids, penicillin, streptomycin, and Dulbecco's phosphate-buffered saline (DPBS) were obtaind from Gibco

Barr virus; FGAR, formylglycinamide ribotide; GDP, guanosine diphosphate; MeSno, 6-methylthioinosine; PHA, phytohemagglutinin; $\mathbf{P i}$, inorganic phosphate; PRPP, 5-phosphoribolsyl 1-pyrophosphate; ribose5-P, ribose-5-phosphate. 
Laboratories (Grand Island, NY), and fetal bovine serum was a product of KC Biological Co. (Lenexa, KS). (Where appropriate, serum was dialyzed for $5 \mathrm{~d}$ at $4^{\circ} \mathrm{C}$ against $20 \mathrm{vol} 0.9 \% \mathrm{NaCl}$ with daily changes of dialysate before filtration through a 0.2- $\mu \mathrm{m}$ Millipore filter.) Ficoll-Paque and Sephadex G-25 were purchased from Pharmacia Fine Chemicals (Piscataway, NJ); phytohemagglutinin M/P (PHA) was obtained from Difco Laboratories, Inc. (Detroit, MI). DE-52 DEAE-cellulose ion-exchanger was obtained from Whatman, Inc. (Clifton, $\mathrm{NJ}$ ) and cellulose thin-layer chromatography plates with fluorescent indicator were obtained from Eastman Kodak Co. (Rochester, NY). Precoated polyethyleniminecellulose thin-layer chromatography sheets were products of $\mathrm{E}$. Merck (Cincinnati, $\mathrm{OH}$ ). Ribose-5-P and all nonradioactive purine compounds were products of Sigma Chemical Co. (St. Louis, MO). Azaserine was purchased from Calbiochem-Behring Corp. (La Jolla, CA). All other reagents were purchased commercially and were of the highest grade generally available. Epstein-Barr (EB) virus was kindly provided by Dr. Elliot Kieff, The University of Chicago.

Patients and controls. Lymphoblast lines were established from six unrelated male patients with purine overproduction and superactive forms of PRPP synthetase previously shown in fibroblasts and/or erythrocytes (3-5, 10, 11; and Becker, M. A., M. J. Losman, E. W. Holmes, I. Mehlman, A. L. Rosenberg, and H. A. Simmonds, manuscript submitted for publication). A catalytic defect is the sole kinetic abnormality demonstrable in the enzymes from three of the patients (T.B., M.C., and A.D.) (3, 11; and Becker, M. A., et al., manuscript submitted for publication), and the enzyme from a fourth patient (N.B.) (10; and Becker, M. A., et al., manuscript submitted for publication) shows only a regulatory defect. Fibroblast PRPP synthetase from a fifth patient (S.M.) shows combined catalytic and regulatory defects (5). In the sixth patient (B.P.), the only kinetic abnormality is a substrate (ribose-5-P) binding defect (4). Lymphoblast lines established from three individuals (C.L., K.C., and L.S.) with normal purine metabolism served as controls. C.L. and K.C. were entirely healthy at the time of initiation of the lymphoblast line, while lymphocytes from L.S. were cultured during an episode of infectious mononucleosis. All six patients served as donors of skin biopsy material for initiation of fibroblast cultures; fibroblast cultures derived from the skin of four normal individuals served as controls in the respective fibroblast studies.

Cell cultures. Lymphoblast lines were initiated from mononuclear cells isolated from 10 to $25 \mathrm{ml}$ of fresh venous blood by centrifugation through Ficoll-Paque (24). Cells were washed three times in RPMI 1640 medium supplemented with $2 \mathrm{mM} \mathrm{L-glutamine,} 15 \%$ fetal bovine serum, $50 \mathrm{U} / \mathrm{ml}$ penicillin, and $50 \mu \mathrm{g} / \mathrm{ml}$ streptomycin (medium A) and were counted on a hemocytometer before resuspension in medium $\mathrm{A}$ at a density of $1.2 \times 10^{6}$ cells $/ \mathrm{ml}$. Portions of the cell suspensions $(5 \mathrm{ml} \mathrm{each})$ from patients T.B., M.C., A.D., and S.M. and from controls C.L. and K.C. were transferred to each of several $25-\mathrm{cm}^{2}$ Falcon flasks, also received $1 \mathrm{ml}$ of medium A containing 100,000 $\mathrm{U}$ of B95-8 EB virus. After a 1 $\mathrm{h}$ incubation in a water bath at $37^{\circ} \mathrm{C}$, cultures were incubated at $37^{\circ} \mathrm{C}$ in a humidified atmosphere of $5 \% \mathrm{CO}_{2}$ in air and, thereafter, were treated as previously described (25). Upon establishment of cultures, the fetal bovine serum concentration in the medium was reduced to $10 \%$ (medium B). Cultures were propagated in medium $B$ at cell densities between 0.25 and $1.5 \times 10^{6} / \mathrm{ml}$ in $75 \mathrm{~cm}^{2}$ Falcon flasks containing no more than 60 $\mathrm{ml}$ per flask.

Four additional lymphoblast lines, two from affected patients (T.B. and B.P.) and two from normal individuals (K.C. and L.S.), were established after addition of rehydrated PHA $(0.1 \mathrm{ml})(26)$ to $5-\mathrm{ml}$ portions of the cell suspensions prepared in medium $\mathrm{A}$, as described above. $\mathrm{Al}$ though not exposed to exogenous EB virus, these cultures were otherwise treated and propagated as above. Lymphoblasts from patient N.B. (10) were provided by Dr. H. Anne Simmonds, Guy's Hospital, London, England.

Fibroblast cultures were initiated from skin biopsy specimens and were propagated in monolayer as previously described (27). The growth medium was Eagle's minimal essential medium containing $2 \mathrm{mM} \mathrm{L}-$ glutamine, $10 \%$ fetal bovine serum, nonessential amino acids, penicillin $(50 \mathrm{U} / \mathrm{ml})$, and streptomycin $(50 \mu \mathrm{g} / \mathrm{ml})$.
Preparation of cell extracts. Lymphoblasts in log phase growth were resuspended in their medium, and, after cell density was determined, an appropriate volume of cell suspension was centrifuged at $800 \mathrm{~g}$ for 5 min. The cell pellet was washed three times in calcium-free DPBS, and cells were resuspended at an appropriate density (usually either $2 \times 10^{7}$ cells $/ \mathrm{ml}$ or $1.5 \times 10^{8}$ cells $/ \mathrm{ml}$ ) in an extraction buffer at $\mathrm{pH} 7.4$ containing $2 \mathrm{mM}$ sodium inorganic phosphate $(\mathrm{Pi}), 1 \mathrm{mM}$ dithiothreitol, and $1 \mathrm{mM}$ EDTA. The cell suspension was then frozen in liquid nitrogen and either stored at $-70^{\circ} \mathrm{C}$ or immediately subjected to further extract preparation and PRPP synthetase assay as described below.

On the day of enzyme assay, cell suspensions were thawed and subjected to two additional cycles of freezing in liquid nitrogen and thawing. Extracts were then centrifuged at $48,000 \mathrm{~g}$ for $20 \mathrm{~min}$ at $4^{\circ} \mathrm{C}$. The supernatant layer (crude extract) was alternatively: dialyzed at $4^{\circ} \mathrm{C}$ for 120 min against $200 \mathrm{vol}$ of extraction buffer before assay (dialyzed extract); or chromatographed on Sephadex G-25 (5) in extraction buffer at $4^{\circ} \mathrm{C}$, and the material eluted at the excluded volume of the column (chromatographed extract) was assayed. On several occasions, lymphoblast PRPP synthetases were partially purified (10-fold to 30 -fold) by treatment of crude extracts of $\sim 5$ to $8 \times 10^{8}$ cells as previously described (5).

Fibroblasts, harvested from subconfluent monolayers by treatment with trypsin and EDTA (5), were washed three times in DPBS, resuspended at densities ranging from 1 to $6 \times 10^{7} \mathrm{cells} / \mathrm{ml}$, and extracted, dialyzed, and assayed for PRPP synthetase activity as described for lymphoblasts. Dialyzed extracts of peripheral blood mononuclear cells were prepared as described above after a portion of the mononuclear cells isolated from the Ficoll-Paque gradient were washed three times in DPBS. On one occasion, a previously described procedure (28) was applied to four blood mononuclear cell populations (one patient, three control), by which the resulting cell preparations were enriched to between 50 and $62 \%$ B lymphocytes before extract preparation.

Measurement of PRPP synthetase activities. Activities of PRPP synthetase in cell extracts were determined by a modification (5) of the twostep assay procedure of Hershko et al. (29). For all lymphoblast lines and fibroblast strains studied, maximal velocities of the PRPP synthetase reaction were measured at eight or more $P i$ concentrations ranging from 0.2 to $32.2 \mathrm{mM}$. Kinetic constants of lymphoblast PRPP synthetases were determined at $1.0 \mathrm{mM} \mathrm{P}_{\mathrm{i}}$ as previously described (5): dissociation constants $\left(K_{\mathrm{D}}\right)$ for substrates and $\mathrm{Mg}^{+2}$; and responses to purine nucleotide feedback inhibitors $\left(\mathrm{I}_{0.5}\right)$. Inhibitors studied were ADP, guanosine diphosphate (GDP), and 6-methylthioinosine (6-methylmercaptopurine ribonucleoside; MeSno) monophosphate $(5,30)$. The latter compound was synthesized, purified, and characterized as previously described (30).

Measurements of PRPP and purine nucleotide metabolism in lymphoblasts. Lymphoblast PRPP concentrations were determined as described by Hershfield and Seegmiller (31). In lymphoblasts harvested during $\log$ phase growth and resuspended in medium B containing $10 \%$ dialyzed bovine serum (medium C), rates of PRPP generation were calculated $(5,15)$ from simultaneously determined values for PRPP concentrations and rates of incorporation of $\left[{ }^{14} \mathrm{C}\right]$ adenine into intracellular purine compounds $(32,33)$.

To estimate rates of purine synthesis de novo in lymphoblasts, rates of incorporation of $\left[{ }^{14} \mathrm{C}\right]$ formate either into the pathway intermediate formylglycinamide ribotide (FGAR) in the presence of the glutamine antagonist azaserine $(27,34,35)$ or into intracellular purines and purines excreted into the incubation medium $(31,36)$ were determined. Cultures incubated overnight in medium $\mathrm{C}$ were centrifuged at $800 \mathrm{~g}$ for $5 \mathrm{~min}$, and cells were resuspended in medium $C$ lacking glutamine. Cell suspensions containing $2 \times 10^{6}$ lymphoblasts in $425 \mu \mathrm{l}$ of the above medium supplemented with $4 \mathrm{mM}$ glycine with or without $0.1 \mathrm{mM}$ azaserine were then prepared; each suspension was exposed to $5 \% \mathrm{CO}_{2}$ in air, and tubes were sealed and incubated in a water bath-shaker at $37^{\circ} \mathrm{C}$ for 15 min. $\left[{ }^{14} \mathrm{C}\right]$ Formate $(25 \mu \mathrm{Ci}$; final concentration, $1 \mathrm{mM})$ and glutamine (final concentration, $10 \mathrm{mM}$ ) were then added to each cell suspension in $75 \mu \mathrm{l}$ of medium $\mathrm{C}$, and incubation was continued for $1 \mathrm{~h}$ before centrifugation of the cell suspensions at $800 \mathrm{~g}$ for $5 \mathrm{~min}$. Supernatant layers were removed and, where appropriate, saved. Cell pellets were rapidly washed four times with medium $\mathrm{C}$. For cells incubated in the 
presence of azaserine, FGAR was extracted from cell pellets with $80 \%$ ethanol, separated from other label-containing compounds, and counted (35). In the case of suspensions incubated in the absence of azaserine, label in intracellular purines was measured after thin layer chromatographic analysis (33) of the supernatant layers of neutralized perchloric acid-treated extracts, and radioactivity in purines excreted into the medium was measured after precipitation of purine compounds with silver nitrate as previously described $(36,37)$. On two occasions, the above technique was modified (37) to utilize cell suspensions of $20 \mathrm{ml}$ containing $20 \times 10^{6}$ cells, which were incubated with $\left[{ }^{14} \mathrm{C}\right]$ formate $(10 \mu \mathrm{Ci}$; final concentration, $10 \mu \mathrm{M}$ ) for $2 \mathrm{~h}$ at $37^{\circ} \mathrm{C}$ before separation of cells and medium for determination of radioactivity in purine compounds.

Other methods. Lymphoblast content of PRPP synthetase was measured by a specific radioassay for immunoreactive enzyme (CRM) previously described in detail (38). In each study, a standard line relating displacement of ${ }^{125}$ I-PRPP synthetase from rabbit antibody to the purified erythrocyte enzyme by a series of concentrations of unlabeled purified erythrocyte PRPP synthetase was generated. Displacement of labeled enzyme by multiple dilutions of dialyzed extracts of each lymphoblast line was tested in duplicate over a three- to fourfold range of labeled enzyme displacement on at least two separate occasions. Slopes of lines relating labeled enzyme displacement by purified erythrocyte PRPP synthetase and by dialyzed lymphoblast extracts agreed to within 3\%, indicating that enzymes from each extract and from normal erythrocytes had similar affinities for the antibody. Enzyme absolute specific activity (activity per unit enzyme protein) was calculated from the results of radioimmunoassay and enzyme activity determinations carried out in parallel in identical extracts. All determinations of protein concentrations were carried out by the method of Lowry et al. (39), using bovine serum albumin as standard.

Electrophoresis of crude lymphoblast and fibroblast extracts was carried out on cellulose acetate gel strips in three different buffer solutions at $\mathrm{pH} 8.5$ as previously described $(18,21,40)$. Electrophoretic migration of PRPP synthetase was examined with an activity stain dependent upon reversal of the usual PRPP synthetase reaction (40). Staining in the presence and absence of PRPP assured specific identification of the enzyme. Thermal inactivation of lymphoblast and fibroblast PRPP synthetases was studied at $57^{\circ} \mathrm{C}$ as described (18). The major histocompatibility antigens (HLA-A and HLA-B) on fibroblasts and lymphoblasts derived from patients T.B., M.C., and A.D. were determined by the Tissue Typing Laboratory of the University of Illinois Medical Center, Chicago, utilizing a complement-dependent cytotoxicity assay (41).

\section{Results}

Characteristics of lymphoblast cultures. Cells derived from normal individuals and patients did not differ in the time required for outgrowth of lymphoblasts after EB virus stimulation (2-6 wk) or PHA exposure (6-9 wk) of blood mononuclear cells. Log phase doubling times for lymphoblast lines ranged from 28 to $43 \mathrm{~h}$, and periodic variations in the doubling times of individual cultures were again noted (42). The comparisons described below among cell lines were made utilizing cultures with doubling times differing by no more than $3 \mathrm{~h}$. Cell lines were propagated from both PHA-treated and EB virus-stimulated lymphocytes of one normal individual (K.C.) and one patient (T.B.). Lectin-treated and virus-treated cultures derived from the same persons were indistinguishable with regard to biochemical and physiological characteristics. Consequently, the studies presented below include data obtained from both lectin-stimulated and virus-stimulated cultures. The HLA-A and HLA-B antigens (four specificities in each case) expressed by the lymphoblasts from each patient tested were identical to those expressed by the fibroblasts from the respective patient, assuring that the cultures of the different cells were derived from the same patient source.
Characteristics of PRPP synthetase activities in lymphoblasts. Maximal velocities of the PRPP synthetase reaction in dialyzed blood mononuclear cell, fibroblast, and lymphoblast extracts assayed at a Pi concentration of $32.2 \mathrm{mM}$ are shown in Table I. Enzyme activities in mononuclear cells and fibroblasts from patients with catalytically altered erythrocyte PRPP synthetases were twofold or more greater than those in the respective control cells. Extracts of B lymphocyte-enriched mononuclear cells from patient A.D. showed enzyme activity 2.2 -fold greater than the mean value in three such extracts from normal individuals (A.D., $727 \mathrm{nmol} / \mathrm{h}$ per $\mathrm{mg}$; mean normal value, $321 \mathrm{nmol} / \mathrm{h}$ per $\mathrm{mg}$ ). The relative increase in enzyme activity at each Pi concentration from 0.2 to $32.2 \mathrm{mM}$ was constant in fibroblasts and mononuclear cells from each patient with a catalytically altered enzyme (not shown). In contrast, maximal PRPP synthetase activities were comparable at all Pi concentrations in lymphoblasts cultured from each of these patients and from normal individuals (Table I; and Fig. 1). In fact, enzyme activities at saturating substrate concentrations were indistinguishable among all lymphoblast lines when the Pi concentration exceeded $\sim 1.5 \mathrm{mM}$. Increased maximal reaction velocity, the hallmark of catalytically aberrant PRPP synthetase $(6-8,11,18)$, was thus not demonstrable in lymphoblast lines even though peripheral blood mononuclear cell populations from which at least two of these cell lines were derived showed increased maximal reaction velocities.

Fig. 1 (inset) shows that enzyme activities were increased at Pi concentrations below $1.5 \mathrm{mM}$ for dialyzed lymphoblast extracts from patients S.M. and N.B. Responses of PRPP synthetases to the addition of the inhibitors ADP, GDP, and MeSno monophosphate were then measured at $1 \mathrm{mM} \mathrm{Pi}$ in chromatographed lymphoblast extracts. The ranges of values for $\mathrm{I}_{0.5}$ determined for inhibitors in extracts of control cell lines were: ADP, 68-83 $\mu \mathrm{M}$; GDP, 90-117 $\mu \mathrm{M}$; and MeSno monophosphate, $138-177 \mu \mathrm{M}$. $\mathrm{I}_{0.5}$ for these compounds fell within the above ranges for lymphoblast PRPP synthetases from patients

Table I. Maximal Velocities of PRPP Synthetases*

\begin{tabular}{cllll}
\hline \multicolumn{5}{c}{ Enzyme activity in dialyzed extracts of: } \\
\cline { 3 - 5 } Group & $\begin{array}{l}\text { Enzyme } \\
\text { defect }\end{array}$ & $\begin{array}{l}\text { Mononuclear } \\
\text { cells }\end{array}$ & Fibroblasts & Lymphoblasts \\
\hline & & $\begin{array}{l}\text { nmol/h/mg } \\
\text { protein }\end{array}$ & $\begin{array}{l}\text { nmol/h/mg } \\
\text { protein }\end{array}$ & $\begin{array}{l}\text { nmol/h/mg } \\
\text { protein }\end{array}$ \\
Normal & None & $260-327(4)$ & $290-457(4)$ & $298-351(3)$ \\
Patient & & & & \\
T.B. & Catalytic & 669 & 1,523 & 357 \\
M.C. & & - & 1,090 & 326 \\
A.D. & & 799 & 1,140 & 346 \\
N.B. & Regulatory & - & 268 & 288 \\
B.P. & Affinity & - & 384 & 317 \\
S.M. & Combined & - & 898 & 352 \\
. & & & & \\
\hline
\end{tabular}

* Enzyme activities were determined by a two-step reaction (5) utilizing saturating substrate concentrations (MgATP, $500 \mu \mathrm{M}$; ribose-5-P, $350 \mu \mathrm{M}$ ) and a Pi concentration of $32.2 \mathrm{mM}$. Values for normal extracts represent ranges of determinations made in duplicate, and parentheses indicate number of normal extracts tested. Values for fibroblast and lymphoblast extracts are means of at least two determinations, each in duplicate. 


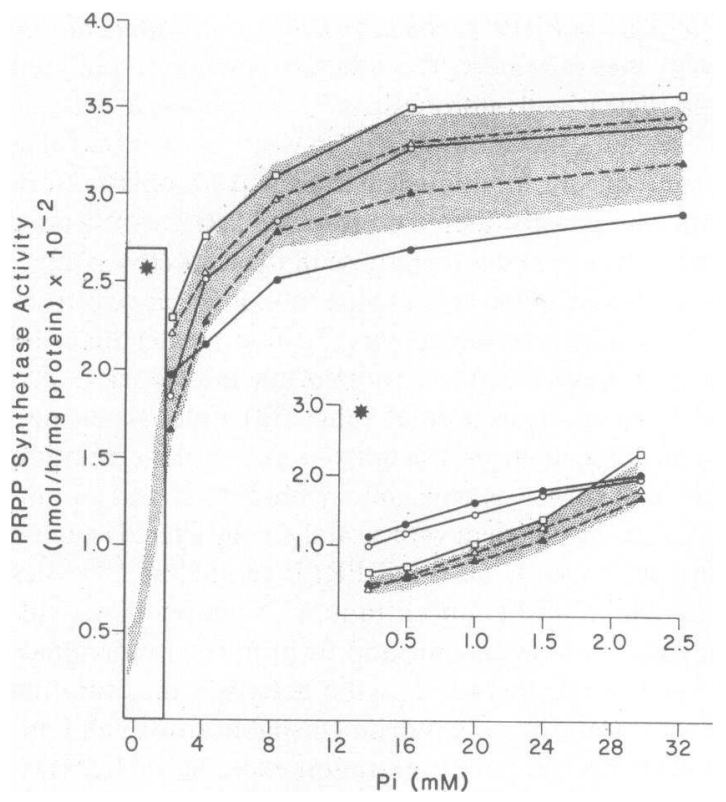

Figure 1. Activation of lymphoblast PRPP synthetases by $\mathrm{Pi}$ in dialyzed extracts. Inset, enzyme activities over the range of from 0.2 to $2.2 \mathrm{mM} \mathrm{Pi}$ in greater detail. Stippled area denotes range of enzyme activities in extracts of lymphoblast derived from three normal individuals. T.B. extract, $\square$; M.C. extract, $\triangle$; A.D. extract, $\triangle$; S.M. extract, o; N.B. extract, $\bullet$. Results obtained with B.P. extract have been omitted, but all values fell in the normal range. Note sigmoidal enzyme activation in all extracts except those of S.M. and N.B. lymphoblasts. Sigmoidal activation reflects normal responsiveness of the enzyme to nucleotide inhibitors (29), incompletely removed by the limited dialysis employed (11). Hyperbolic activation in S.M. and N.B. extracts suggests diminished inhibitor responsiveness $(5,11,19)$. Note also similarity in maximal enzyme activities of all extracts at Pi concentrations $>1.5 \mathrm{mM}$.

with catalytic and substrate binding defects. Patient S.M. lymphoblast PRPP synthetase showed increased resistance to inhibition by all three nucleotides $\left(I_{0.5}\right.$ for: ADP, $195 \mu \mathrm{M}$; GDP, 355 $\mu \mathrm{M}$; MeSno monophosphate, $540 \mu \mathrm{M}$ ). In contrast, N.B. lymphoblast enzyme showed increased resistance to the noncompetitive inhibitors GDP $(18,43)$ and MeSno monophosphate (30) $\left(\mathrm{I}_{0.5}\right.$, respectively, $610 \mu \mathrm{M}$ and $\left.840 \mu \mathrm{M}\right)$ but not to the competitive inhibitor ADP $(18,43)$. These patterns of inhibitor resistance were also observed when assays were carried out using partially purified preparations of lymphoblast PRPP synthetases (not shown).

Dissociation constants for substrates and magnesium were also determined in chromatographed preparations of each lymphoblast PRPP synthetase. The ranges of values of $K_{\mathrm{D}}$ for MgATP, ribose-5-P, and $\mathrm{Mg}^{2+}$, respectively, were $11-17 \mu \mathrm{M}$, 18-29 $\mu \mathrm{M}$, and $41-49 \mu \mathrm{M}$ in extracts of the control cell lines. The only abnormal value detected among patients' extracts was a threefold reduced $K_{\mathrm{D}}(6 \mu \mathrm{M})$ of the enzyme in cells derived from patient B.P. for the substrate ribose-5-P. The patterns and magnitudes of inhibitor resistance shown by S.M. and N.B. lymphoblast PRPP synthetases and the increased affinity of the BP lymphoblast enzyme for ribose-5-P were quite similar to the specific defects shown by the fibroblast enzymes from the respective patients ( 5,44 ; and Becker, M. A., et al., manuscript submitted for publication). Thus, both regulatory and substrate binding defects in PRPP synthetases were demonstrable in lymphoblasts, while catalytic defects were not. In fact, S.M. lymphoblasts expressed the regulatory defect but not the catalytic defect previously demonstrated to co-exist in fibroblasts from this patient (5).

PRPP and purine nucleotide synthesis in lymphoblasts. PRPP concentrations and rates of PRPP generation in lymphoblast lines are presented in Table II. No significant differences in PRPP concentrations or generation were detected between normal lymphoblast lines and lines derived from patients with catalytically altered fibroblast PRPP synthetases. In contrast, PRPP concentrations and generation were increased in lymphoblasts from patients S.M., N.B., and B.P. Similarly, rates of purine synthesis de novo were increased only in lymphoblasts from these patients (Table II). Lymphoblast lines bearing regulatory and substrate binding defects in PRPP synthetase excreted an in-

Table II. PRPP Concentrations and Rates of PRPP Generation and of Purine Synthesis de novo in Lymphoblast Lines*

\begin{tabular}{|c|c|c|c|c|c|c|}
\hline \multirow[b]{2}{*}{ Group } & \multirow[b]{2}{*}{ Enzyme defect } & \multicolumn{2}{|l|}{ PRPP } & \multicolumn{3}{|c|}{$\left[{ }^{14} \mathrm{C}\right]$ formate incorporation into: } \\
\hline & & Concentration & Generation & FGAR & Total purines & Medium purines \\
\hline & & pmol/ $/ 10^{6}$ cells & pmol/h per $10^{6}$ cells & \multicolumn{2}{|c|}{$\left(\mathrm{cpm} / \mathrm{h}\right.$ per $10^{6}$ cells $) \times 10^{-3}$} & $\%$ of total purines \\
\hline Normal & None & $22-31$ & $460-595$ & $2.5-4.0$ & $7.4-10.4$ & $5.8-10.1$ \\
\hline \multicolumn{7}{|l|}{ Patient } \\
\hline T.B. & Catalytic & 29 & 480 & 2.8 & 11.2 & 9.1 \\
\hline M.C. & & 24 & 571 & 4.2 & 9.2 & 7.1 \\
\hline A.D. & & 33 & 636 & 3.2 & 10.1 & 9.6 \\
\hline N.B. & Regulatory & 54 & 1,221 & 8.5 & 18.5 & 31.1 \\
\hline B.P. & Affinity & 52 & 1,092 & 8.2 & 17.7 & 22.7 \\
\hline S.M. & Combined & 61 & 1,330 & 11.5 & 29.5 & 41.1 \\
\hline
\end{tabular}

* Lymphoblast PRPP concentrations were determined as described above $(31)$. Incorporation of $\left[{ }^{14} \mathrm{C}\right]$ adenine into purine compounds $(5,32,33)$ and incorporation of labeled formate into FGAR $(35)$ and into total purines $(31,36,37)$ were measured as described previously and in Methods. PRPP generation was calculated by the formula described (15), which takes into account incorporation of $\left[{ }^{14} \mathrm{C}\right]$ adenine and PRPP concentrations at each of several incubation times as well as the concentration of PRPP at zero min. In the determinations of purine synthesis, the proportion of total labeled purines detected in the medium (last column) agreed within $\sim 5 \%$ for each cell line by the two procedures employed (36, 37). Values for normal groups are presented as ranges of determinations in three cell lines. All values presented are the means of at least two separate determinations. 
creased proportion of newly synthesized purines into the medium. Overall, there was a close correlation in lymphoblast lines between increased rates of intracellular PRPP and purine synthesis and demonstrable kinetic derangement of PRPP synthetase in vitro.

Properties of lymphoblast PRPP synthetases. The uniform and apparently specific absence of phenotypic expression of catalytic superactivity in lymphoblasts suggested that PRPP synthetases in at least some lymphoblast lines might differ substantially in amounts, absolute specific activities, and/or additional properties relative to the respective enzymes previously studied in detail in erythrocytes and fibroblasts. Certain immunochemical and physical properties of lymphoblast PRPP synthetases were, therefore, examined.

Among six normal-derived and patient-derived lymphoblast lines, PRPP synthetase CRM differed by $<20 \%$ (Table III). Absolute specific activities of PRPP synthetase (Table III) were very similar for all lymphoblast lines tested and were in the range of values for PRPP synthetase absolute specific activities measured in erythrocytes and fibroblasts from normal individuals (38).

In additional studies, aberrant electrophoresis and thermal stability properties of the enzyme, previously associated with phenotypic expression of some catalytic defects in fibroblasts (18, 21; and Becker, M. A., et al., manuscript submitted for publication), were sought in lymphoblasts. Cellulose acetate gel electrophoresis studies of fibroblast extracts $(21,41)$ showed reduced electrophoretic mobilities of PRPP synthetases from two patients (T.B. and A.D.) with catalytic overactivity (Fig. 2). In contrast, PRPP synthetases in lymphoblast extracts from normal individuals and from all patients with catalytic or combined defects in the enzyme (including T.B. and A.D.) migrated with the same electrophoretic mobility, one which was indistinguishable from that of normal fibroblast PRPP synthetase. Studies of the thermal stabilities of fibroblast and lymphoblast PRPP synthetases at $57^{\circ} \mathrm{C}$ showed a similar discordance: as previously demonstrated $(5,18)$ S.M., and T.B. fibroblast PRPP synthetases showed reduced thermal stability; PRPP synthetases from all

Table III. Characterization of Lymphoblast PRPP Synthetase

\begin{tabular}{cllll}
\hline \multicolumn{5}{c}{ ERPP synthetase* } \\
\cline { 3 - 5 } Group & $\begin{array}{l}\text { Enzyme } \\
\text { defect }\end{array}$ & $\begin{array}{l}\text { Specific } \\
\text { activity }\end{array}$ & CRM & $\begin{array}{l}\text { Absolute } \\
\text { specific activity }\end{array}$ \\
\hline & & $\begin{array}{l}\text { nmol/h per } m g \\
\text { protein }\end{array}$ & $\mu g / m g$ protein & $\begin{array}{l}\text { nmol/h per } m g \\
\text { CRM }\end{array}$ \\
Normal & & & & \\
C.L. & None & 320 & 1.38 & 232,000 \\
L.S. & & 305 & 1.17 & 261,000 \\
Patient & & & & \\
T.B. & Catalytic & 355 & 1.34 & 265,000 \\
M.C. & & 340 & 1.39 & 245,000 \\
A.D. & & 336 & 1.23 & 273,000 \\
S.M. & Combined & 320 & 1.16 & 278,000 \\
\hline
\end{tabular}

* Enzyme activity at Pi concentration of $32.2 \mathrm{mM}$ (5) and CRM (39) were measured as described, and absolute specific activities of PRPP synthetase were calculated from these data. Values presented as means of at least two determinations, each carried out in duplicate over a three- to fourfold range of radiolabeled PRPP synthetase displacement.

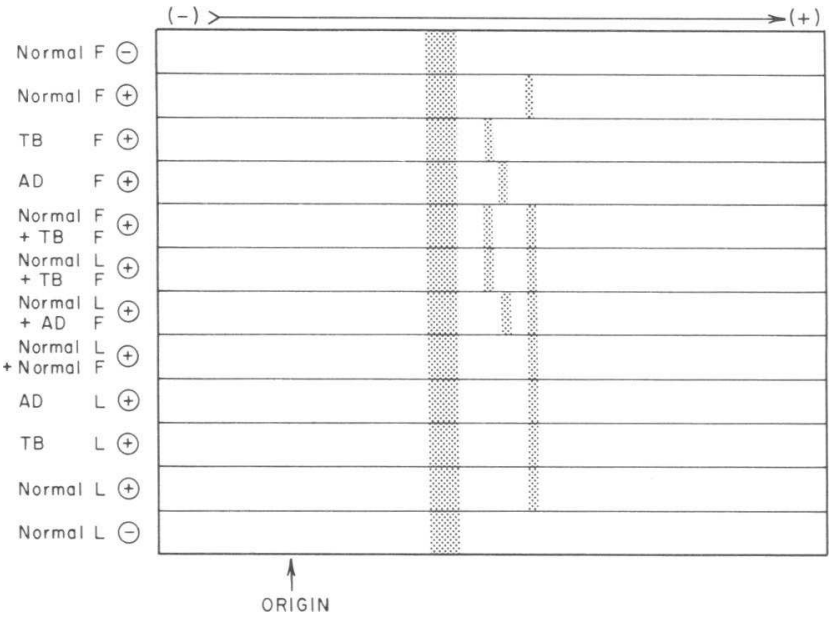

Figure 2. Schematic representation of cellulose acetate strip electrophoresis of lymphoblast (L) and fibroblast (F) PRPP synthetases. Crude cell extracts (11-13.5 $\mu \mathrm{g}$ of protein) were applied to duplicate cellulose acetate strips (Biomedica; Millipore Corp., Bedford, MA), and electrophoresis was carried out at $4^{\circ} \mathrm{C}$ for $45 \mathrm{~min}$ in a buffer system at $\mathrm{pH} 8.5$ as previously described (21). After electrophoresis, one strip of each pair was stained at $37^{\circ} \mathrm{C}(41)$ with PRPP in the staining solution $(+)$. The duplicate strip was stained in an identical solution from which PRPP was omitted (-) to identify nonspecific staining. Bands seen only after development in the presence of PRPP represent PRPP synthetase. Since control strips for all other fibroblast and lymphoblast extracts showed the patterns seen for normal extracts in the top and bottom strips, respectively, additional control strips have been omitted.

lymphoblast lines were, however, indistinguishable with respect to thermal stability (data not shown).

\section{Discussion}

Long-term lymphoblastoid lines have been used increasingly in recent years to study biochemical and genetic mechanisms in the regulation of human purine metabolism $(25,26,31,45-52)$. Many studies have employed the splenic B lymphocyte-derived WI-L2 cell line (53) and mutant cell lines selected from WI-L2, including those deficient in hypoxanthine phosphoribosyltransferase $(25,31,46,48-51)$, adenosine kinase $(46,47)$, and adenine phosphoribosyltransferase (47). In addition, lymphoblastoid lines derived directly from B lymphocytes of patients with inborn errors of purine metabolism have been studied $(25,26,51)$, most notably cell lines from patients with partial $(25)$ or severe deficiencies of hypoxanthine phosphoribosyltransferase $(26,54)$. The elegant work of Wilson and Kelley (25) has established the suitability of lymphoblastoid cell lines as a source of cells for the detection, isolation, and characterization of structural variants of human HPRT. This work has, in turn, reinforced the view that lymphoblastoid lines provide both a convenient and reliable system for the study of inborn errors of human metabolism (55).

The results of the current study show selectivity in the expression of PRPP synthetase superactivity in lymphoblast lines. Lymphoblasts derived from patients N.B. and B.P. showed kinetic defects in the enzyme identical to those found in fibroblasts from the respective patient $(4,44$; and Becker, M. A., et al., manuscript submitted for publication) and also possessed metabolic properties previously shown in fibroblasts to be characteristic of cells bearing superactive PRPP synthetases $(4,5,7$, 
$14,15)$. In contrast, neither increased enzyme maximal reaction velocity nor abnormalities of PRPP and purine nucleotide synthesis were demonstrable in lymphoblasts derived from three patients with isolated catalytic superactivity of erythrocyte and fibroblast PRPP synthetases. PRPP synthetase in lymphoblasts from these patients also showed immunochemical and physical properties indistinguishable from those of the normal lymphoblast enzyme, in some cases failing to confirm differences in electrophoresis and thermal stability properties observed in fibroblast strains from the respective patients (18, 21; and Becker, M. A., et al., manuscript submitted for publication). In lymphoblasts from these individuals, then, no evidence for phenotypic expression of enzyme superactivity was detected. Between the extremes of full expression and nonexpression, an intermediate case was encountered for patient S.M., whose fibroblast enzyme is altered in both catalytic and regulatory properties (5) and whose lymphoblasts showed a feedback resistant enzyme and excessive rates of PRPP and purine synthesis unaccompanied by increased enzyme maximal reaction velocity. Thus, catalytically superactive PRPP synthetase was unexpressed in lymphoblasts from all four patients in whom catalytic defects in the fibroblast enzyme had been established $(4,5$; and Becker, M. A., et al., manuscript submitted for publication), even in the setting of a co-existing regulatory defect which was expressed.

On the basis of these findings, it seems likely that the reliability of lymphoblast lines for studies of the genetic bases of PRPP synthetase superactivity may well be limited to cell lines in which kinetic abnormalities in enzyme activity and evidence for alteration in PRPP and purine nucleotide synthesis are identifiable. The absence of catalytic defects in lymphoblast lines derived from patients with such defects in fibroblasts raises questions about the nature of this class of inherited PRPP synthetase superactivity and the determinants of its expression. Among potential explanations for absence of expression of catalytic superactivity, the results of immunochemical studies (Table III) made unlikely the possibility that differences in concentrations of PRPP synthetases among cell lines were obscuring differences in absolute specific activities of individual forms of the enzyme. These studies also provided evidence against selective activation of normal PRPP synthetase as an explanation for comparable catalytic activity in normal-derived and patient-derived lymphoblasts. These and additional studies of physical properties of the enzymes favored the suggestion that lymphoblast PRPP synthetases from patients with catalytic superactivity are structurally different from their enzyme counterparts in fibroblasts and erythrocytes. Moreover, since increased PRPP synthetase activities were found in extracts of freshly isolated peripheral blood mononuclear cells from the two patients with catalytic superactivity tested, expression of catalytic defects in B cells before transformation into lymphoblasts seems likely. Thus, the selective loss of expression of catalytic superactivity in lymphoblasts appears to reflect an event occurring in (or missing from) transformed lymphocytes, which specifically effects the structure of the enzyme. At which level between the structural gene coding for PRPP synthetase and the active enzyme product such alteration is effected is uncertain.

We believe that the data presented make unlikely several possible explanations for absence of expression of catalytic superactivity in lymphoblasts. These include spontaneous reversion to normal of all and only the genetic defects underlying catalytic superactivity and the existence of a structural gene for lympho- blast PRPP synthetase different from that coding for the erythrocyte and fibroblast forms of the enzyme. Similarly, absolute specific activities of lymphoblast PRPP synthetases provide no support for a model, suggested by the work of Martin and colleagues $(56,57)$, in which catalytically superactive PRPP synthetase is an induced and activated form in untransformed cells, with loss of the catalytically superactive phenotype representing conversion of normal enzyme to the induced and activated form during lymphocyte transformation.

Posttranslational modification of the enzyme is another mechanism by which the structure and activity of lymphoblast PRPP synthetase may differ from that of the enzyme in other cells. If, for example, expression of catalytic superactivity requires a posttranslational alteration unique to these genetically altered forms of the enzyme, an activity mediating this modification may not be expressed in lymphoblasts. The possibility of such a mechanism must remain speculative in the absence of evidence to affirm or deny its operation. Nor is it possible to exclude with certainty an alternative hypothesis in which the primary genetic defect underlying catalytic superactivity resides in the gene coding for a posttranslational modifier of structurally normal PRPP synthetase. Studies aimed at establishing the precise nature of inherited defects underlying PRPP synthetase superactivity and at evaluating the possibility of posttranslational modification of the enzyme will likely provide insight into the selective expression of enzyme superactivity in lymphoblasts.

\section{Acknowledgments}

The authors gratefully acknowledge the excellent technical assistance of Ms. Sharon Hecker and Ms. Janine Raymond and efficient manuscript preparation by Ms. Pat Ernst and Ms. Claire Doyle. We thank Dr. Ira Mehlman (Walter Reed Army Medical Center, Washington, DC) and Dr. Alan L. Rosenberg (Denver, CO) for providing access to their patients; and Dr. Harry Gruber (University of California, San Diego) for providing tissue culture material from several patients.

This work was supported in part by U.S. Public Health Service grant AM-28554 from the National Institutes of Health and by a grant from the Arthritis Foundation, Illinois Chapter.

\section{References}

1. Kornberg, A., I. Lieberman, and E. S. Simms. 1955. Enzymatic synthesis and properties of 5-phosphoribosylpyrophosphate. J. Biol. Chem. 215:389-402.

2. Sperling, O., P. Boer, S. Persky-Brosh, E. Kanarek, and A. deVries. 1972. Altered kinetic property of erythrocyte phosphoribosylpyrophosphate synthetase in excessive purine production. Rev. Eur. Etud. Clin. Biol. 17:703-706.

3. Becker, M. A., L. J. Meyer, A. W. Wood, and J. E. Seegmiller. 1973. Purine overproduction in man associated with increased phosphoribosylpyrophosphate synthetase activity. Science (Wash. DC). 179: 1123-1126.

4. Becker, M. A. 1976. Patterns of phosphoribosylpyrophosphate and ribose-5-phosphate concentration and generation in fibroblasts from patients with gout and purine overproduction. J. Clin. Invest. 57:308318.

5. Becker, M. A., K. O. Raivio, B. Bakay, W. B. Adams, and W. L. Nyhan. 1980. Variant human phosphoribosylpyrophosphate synthetase altered in regulatory and catalytic functions. J. Clin. Invest. 65:109-120.

6. Akaoka, I., S. Fujimori, N. Kamatani, F. Takeuchi, E. Yano, Y. Nishida, A. Hashimoto, and Y. Horiuchi. 1981. A gouty family with 
increased phosphoribosylpyrophosphate synthetase activity: case reports, familial studies, and kinetic studies of the abnormal enzyme. J. Rheumatol. 8:563-573.

7. Becker, M. A., M. J. Losman, P. Itkin, and P. A. Simkin. 1982. Gout with superactive phosphoribosylpyrophosphate synthetase due to increased enzyme catalytic rate. J. Lab. Clin. Med. 99:495-511.

8. Nishida, Y., I. Akaoka, and Y. Horiuchi. 1981. Altered isoelectric property of a superactive 5-phosphoribosyl-1-pyrophosphate (PRPP) synthetase in a patient with clinical gout. Biochem. Med. 26:387-394.

9. Lejeune, E., M. Bouvier, B. Mousson, G. Llorca, and P. Baltassat. 1979. Anomalie de la phosphoribosylpyrophosphate synthetase dans deux cas de goute à début précoce. Rev. Rhum. 46:457-465.

10. Simmonds, H. A., D. R. Webster, J. Wilson, and S. Lingham. 1982. An X-linked syndrome characterized by hyperuricemia, deafness, and neurodevelopmental abnormalities. Lancet. II:68-70.

11. Losman, M. J., S. Hecker, S. Woo, and M. A. Becker. 1984. Diagnostic evaluation of phosphoribosylpyrophosphate synthetase activities in hemolysates. J. Lab. Clin. Med. 103:932-943.

12. Muller, M. M., and O. Frank. 1974. Lipid and purine metabolism in benign symmetric lipomatosis. Adv. Exp. Med. Biol. 41:509-518.

13. Sperling, O., P. Boer, S. Brosh, E. Zoref, and A. deVries. 1978. Overproduction disease in man due to enzyme feedback resistance mutation. Enzyme (Basel). 23:1-9.

14. Zoref, E., A. deVries, and O. Sperling. 1975. Mutant feedbackresistant phosphoribosylpyrophosphate synthetase associated with purine overproduction and gout. J. Clin. Invest. 56:1093-1099.

15. Becker, M. A., L. J. Meyer, and J. E. Seegmiller. 1973. Gout with purine overproduction due to increased phosphoribosylpyrophosphate synthetase activity. Am. J. Med. 55:232-242.

16. Nyhan, W. L., J. A. Jones, A. J. Teberg, L. Sweetman, and L. G. Nelson. 1969. A new disorder of purine metabolism with behavioral manifestations. J. Pediatr. 74:20-27.

17. Becker, M. A., K. O. Raivio, and J. E. Seegmiller. 1979. Synthesis of phosphoribosylpyrophosphate in mammalian cells. Adv. Enzymol. Relat. Areas Mol. Biol. 49:281-306.

18. Becker, M. A., P. J. Kostel, and L. J. Meyer. 1975. Human phosphoribosylpyrophosphate synthetase. Comparison of purified normal and mutant enzymes. J. Biol. Chem. 250:6822-6830.

19. Sperling, O., S. Persky-Brosh, P. Boer, and A. deVries. 1973. Human erythrocyte phosphoribosylpyrophosphate synthetase mutationally altered in regulatory properties. Biochem. Med. 7:389-395.

20. Zoref, E., A. deVries, and O. Sperling. 1977. X-linked pattern of inheritance of gout due to mutant feedback resistant phosphoribosylpyrophosphate synthetase. Adv. Exp. Med. Biol. 76A:287-292.

21. Yen, R. C. K., W. B. Adams, C. Lazar, and M. A. Becker. 1978. Evidence for X-linkage of human phosphoribosylpyrophosphate synthetase. Proc. Natl. Acad. Sci. USA. 75:482-485.

22. Becker, M. A., L. J. Meyer, W. H. Huisman, C. Lazar, and W. B. Adams. 1977. Human erythrocyte phosphoribosylpyrophosphate synthetase. Subunit analysis and states of subunit association. J. Biol. Chem. 252:3911-3918.

23. Becker, M. A., R. C. K. Yen, P. Itkin, S. J. Goss, J. E. Seegmiller, and B. Bakay. 1979. Regional localization of the gene for human phosphoribosylpyrophosphate synthetase on the X-chromosome. Science (Wash. DC). 203:1013-1019.

24. Boyum, A. 1968. Isolation of mononuclear cells and granulocytes from human blood. Scand. J. Clin. Lab. Invest. 21(Suppl. 97):77-89.

25. Wilson, J. M., B. W. Baugher, P. M. Mattes, P. E. Daddona, and W. N. Kelley. 1982. Human hypoxanthine-guanine phosphoribosyltransferase. Demonstration of structural variants in lymphoblastoid cells derived from patients with a deficiency of the enzyme. J. Clin. Invest. 69:706-715.

26. Choi, K. W., and A. D. Bloom. 1970. Biochemically marked lymphocytoid lines: establishment of Lesch-Nyhan cells. Science (Wash. DC). 170:89-90.

27. Rosenbloom, F. M., J. F. Henderson, I. C. Caldwell, W. N. Kelley, and J. E. Seegmiller. 1968. Biochemical bases of accelerated purine bio- synthesis in human fibroblasts lacking hypoxanthine-guanine phosphoribosyltransferase. J. Biol. Chem. 243:1166-1173.

28. Weiner, M. S., C. Bianco, and V. Nussenzweig. 1973. Enhanced binding of neuraminidase-treated sheep erythrocytes to human T lymphocytes. Blood. 42:939-946.

29. Hershko, A., A. Razin, and J. Mager. 1969. Regulation of the synthesis of 5-phosphoribosyl-1-pyrophosphate in intact red blood cells and in cell-free preparations. Biochim. Biophys. Acta. 184:64-76.

30. Yen, R. C. K., K. O. Raivio, and M. A. Becker. 1981. Inhibition of phosphoribosylpyrophosphate synthesis in human fibroblasts by 6methylthioinosinate. J. Biol. Chem. 256:1839-1845.

31. Hershfield, M. S., and J. E. Seegmiller. 1977. Regulation of de novo purine synthesis in human lymphoblasts. Similar rates of de novo synthesis during growth by normal cells and mutants deficient in hypoxanthine-guanine phosphoribosyltransferase activity. J. Biol. Chem. 252:6002-6010.

32. Raivio, K. O., and J. E. Seegmiller. 1983. Adenine, hypoxanthine and guanine metabolism in fibroblasts from normal individuals and patients with hypoxanthine phosphoribosyltransferase deficiency. Biochim. Biophys. Acta. 299:273-282.

33. Crabtree, G. W., and J. F. Henderson. 1971. Rate limiting steps in the conversion of purine ribonucleotides in Ehrlich ascites tumor cells in vitro. Cancer Res. 31:985-991.

34. Henderson, J. F. 1962. Feedback inhibition of purine biosynthesis in ascites tumor cells. J. Biol. Chem. 237:2631-2635.

35. Boyle, J. A., K. O. Raivio, M. A. Becker, and J. E. Seegmiller. 1972. Effects of nicotinic acid on human fibroblast purine synthesis. Biochim. Biophys. Acta. 269:179-183.

36. Martin, D. W., Jr., and N. T. Owen. 1972. Repression and derepression in purine biosynthesis in mammalian hepatoma cells in culture. J. Biol. Chem. 247:5477-5485.

37. Ullman, B., M. A. Wormsted, M. B. Cohen, and D. W. Martin. 1982. Purine overproduction in cultured murine lymphoma cells deficient in adenylosuccinate synthetase: genetic model for inherited hyperuricemia and gout. Proc. Natl. Acad. Sci. USA. 79:5127-5131.

38. Itkin, P., S. Woo, and M. A. Becker. 1984. Human phosphoribosylpyrophosphate synthetase: radiochemical quantitation in erythrocytes and fibroblasts. J. Lab. Clin. Med. 104:96-109.

39. Lowry, O. H., N. J. Rosebrough, A. L. Farr, and R. J. Randall. 1951. Protein measurement with Folin phenol reagent. J. Biol. Chem. 193:265-275.

40. Johnson, M. G., S. Rosenzweig, R. L. Switzer, M. A. Becker, and J. E. Seegmiller. 1974. Evaluation of the role of 5-phosphoribosyl1-pyrophosphate synthetase in congential hyperuricemia and gout. A simple isotopic assay and an activity stain for the enzyme. Biochem. Med. 10:266-275.

41. Mittal, K. K., M. R. Mickey, E. R. Singal, and P. I. Terasaki. 1968. Serotyping for homotransplantation. XVIII. Refinement of microdroplet lymphocyte cytotoxicity test. Transplantation (Baltimore). 6: 913-927.

42. Huisman, W. H., K. O. Raivio, and M. A. Becker. 1979. Simultaneous estimation of rates of pyrimidine and purine nucleotide synthesis de novo in cultured human cells. J. Biol. Chem. 254:12595-12602.

43. Fox, I. H., and W. M. Kelley. 1972. Human phosphoribosylpyrophosphate synthetase. Kinetic mechanism and endproduct inhibition. J. Biol. Chem. 247:2126-2131.

44. Becker, M. A., and J. E. Seegmiller. 1975. Recent advances in the identification of enzyme abnormalities underlying excessive purine synthesis in man. Arthritis Rheum. 18(Suppl.):687-694.

45. Wood, A. W., and J. E. Seegmiller. 1973. Properties of 5-phosphoribosyl-1-pyrophosphate amidotransferase from human lymphoblasts. J. Biol. Chem. 248:138-143.

46. Hershfield, M. S., and J. E. Seegmiller. 1977. Regulation of de novo purine biosynthesis in human lymphoblasts. Coordinate control of proximal (rate-determining) steps and the inosinic acid branch point. $J$. Biol. Chem. 251:7348-7354.

47. Hershfield, M. S., F. F. Snyder, and J. E. Seegmiller. 1977. Adenine 
and adenosine are toxic to human lymphoblast mutants defective in purine salvage. Science (Wash. DC). 197:1284-1287.

48. Lever, J. E., G. Nuki, and J. E. Seegmiller. 1974. Expression of purine overproduction in a series of 8-azaguanine-resistant diploid human lymphoblast lines. Proc. Natl. Acad. Sci. USA. 71:2679-2683.

49. Willis, R. C., and J. E. Seegmiller. 1980. Increases in purine excretion and rate of synthesis by drugs inhibiting IMP dehydrogenase and adenylosuccinate synthetase activities. $A d v$. Exp. Med. Biol. 122B: 237-241.

50. Pilz, R. B., R. C. Willis, and G. R. Boss. 1984. The influence of ribose-5-phosphate availability on purine synthesis of cultured human lymphoblasts and mitogen-stimulated lymphocytes. J. Biol. Chem. 259: 2927-2935.

51. Boss, G. R. 1984. Decreased phosphoribosylpyrophosphate as the basis for decreased purine synthesis during amino acid starvation of human lymphoblasts. J. Biol. Chem. 259:2936-2941.

52. Glade, P. R., and N. G. Beratis. 1976. Long-term lymphoid cell lines in the study of human genetics. In Progress in Medical Genetics. A. G. Steinberg, A. G. Bearn, A. G. Motulsky, and B. Childs, editors. W. B. Saunders Co., Philadelphia. 1:1-48.

53. Levy, J., M. Virolainen, and V. Defendi. 1968. Human lymphoblastoid lines from lymph node and spleen. Cancer. 22:517-524.

54. Wood, A. W., M. A. Becker, and J. E. Seegmiller. 1973. Purine nucleotide synthesis in lymphoblasts cultured from normal subjects and a patient with Lesch-Nyhan syndrome. Biochem. Genet. 9:261-275.

55. Brock, D. J. H. 1978. Inborn errors of metabolism. In The Biochemical Genetics of Man. D. J. H. Brock and O. Mayo, editors. Academic Press, Inc., London. Second ed. 469-560.

56. Chambers, D. A., D. W. Martin, Jr., and Y. Weinstein. 1974. The effect of cyclic nucleotides on purine biosynthesis and the induction of PRPP synthetase during lymphocyte activation. Cell. 3:375-380.

57. Green, C. D., and D. W. Martin, Jr. 1974. A direct, stimulating effect of cyclic GMP on purified phosphoribosylpyrophosphate synthetase and its antagonism by cyclic AMP. Cell. 2:241-245. 